\title{
WINGFLAP DIALECTS IN THE FLAPPET LARK MIRAFRA RUFOCINNAMOMEA
}

The Flappet Lark Mirafra rufocinnamomea is a widespread species inhabiting lightly wooded, grassy country in Africa, and its common name well describes its most conspicuous sound. During the breeding season the birds often fly about over grassy clearings or bare areas in the open woodland and make flapping sounds with their wings. The wingflaps are more often heard than is song, and Wickler (1967) thought song in this lark had been completely replaced as an auditory signal by the mechanical sound of the winghlaps, in contrast to some other Mirafra larks that make noises with their wings and also sing.

Flappet Larks were observed in northern Nigeria in July and August 1968 and in the Northern Province of Zambia in March 1972. The larks flew around slowly at heights of about $50-100 \mathrm{~m}$ and sometimes were barely visible while they flapped at the higher altitudes. The wings during flapping appeared to be held more stiffly out from the sides than during the normal flight. Noise from flapping carried over a few hundred meters and was as loud as or louder than the songs of some other larks that sing in flight, e.g. the Horned Lark or Shore Lake Eremophila alpestris and the Skylark Alauda arvensis.

The individual flap notes are grouped into discreet bursts, and several bursts are regularly given in a flapping series that is repeated without any noticeable variation in an individual bird. The flap notes are characterised by abrupt pulses of noise that cover a wide range of frequencies (Fig. 1). The lower frequencies are the louder and the sound energy becomes progressively less at the higher frequencies. The apparent differences in the frequency spectrum of flap notes within these and the following audiospectrographs are evidently not biologically significant but rather are artifacts of the loudness of the sounds recorded and analysed on the Sonagraph, and the apparent differences in amplitude between flaps of a series may result from the changing distance and the direction of flight of the bird from the microphone.

A tape recording of one individual near Zaria, Nigeria (Fig. 1 (a)) showed that each wingflap series was repeated with no visible audiospectrographic variation four times by the bird. At least two other individuals were heard flapping at Zaria, and though they were not tape recorded they were apparently identical in flapping pattern to the first with two short bursts and then a longer burst of nearly a second's duration. The phrasing and

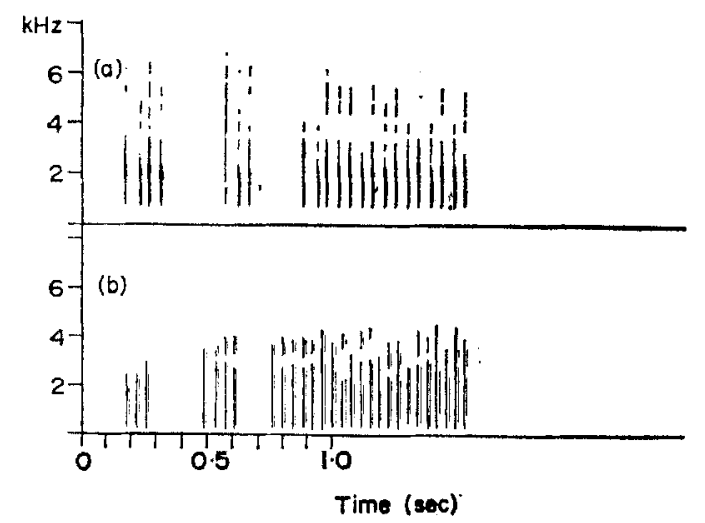

Figure 1. (a) Audiospectrograph of the wingflap sounds of a Flappet Lark recorded at Ahmadu Bello University, Zaria, Nigeria, on 19 July 1968 . Time is measured on the abscissa and frequency on the ordinate. (b) Audiospectrograph of the wingbeat sounds of a Flappet Lark in Tanzania, reproduced by tracing with a planimeter, from Wickler (1967). 
timing of the wingflaps of larks at Zaria are nearly identical with those of a bird recorded by Wickler (1967) in Tanzania, nearly $3,000 \mathrm{~km}$ to the east (Fig. 1 (b)).

Larks were observed and recorded in four localities in Zambia: $1 \mathrm{~km}$ NW Sumbu Lodge ( $\left.8^{\circ} 30^{\prime} \mathrm{S}, 30^{\circ} 27^{\prime} \mathrm{E}\right), 10 \mathrm{~km}$ SW Bulaya $\left(8^{\circ} 37^{\prime} \mathrm{S}, 30^{\circ} 04^{\prime} \mathrm{E}\right)$, Kundabwika Falls $\left(9^{\circ} 12^{\prime} \mathrm{S}\right.$, $\left.29^{\circ} 20^{\prime} \mathrm{E}\right)$, and $20 \mathrm{~km} \mathrm{~W}$ Kasama $\left(10^{\circ} 10^{\prime} \mathrm{S}, 31^{\circ} 10^{\prime} \mathrm{E}\right)$. Two larks were heard and recorded at Sumbu and at Kundabwika Falls, two were recorded and two more heard near Bulaya, and one was recorded and one or two more were heard west of Kasama. Within any one locality all larks had a shared wingfiap pattern (Fig. 2). At Sumbu the larks all had three bursts in each flapping series and the number and timing of the wing noises was the same both in the repeated sequences of flapping series of a single bird and in the flapping series of different birds taped as they alternated flapping over adjacent or neighbouring display areas. Sumbu birds and Bulaya birds all had three bursts per series but differed in the Sumbu birds having the last flapping burst the longest one and in the Bulaya birds having the first burst the longest. The two Kundabwika Falls birds had four bursts in a series and the Kasama birds had three bursts all about the same in duration and number of flaps.

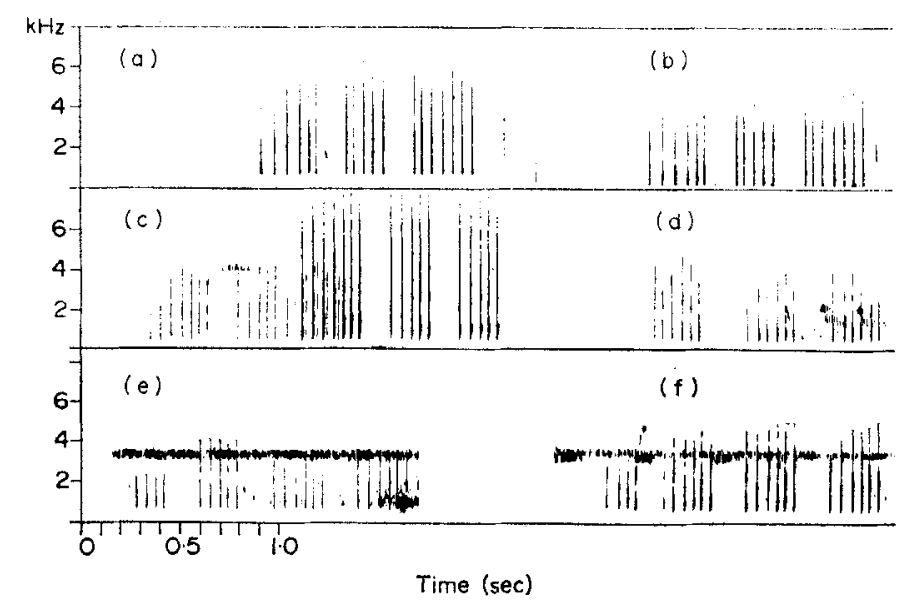

FIGURE 2. Audiospectrographs of the wingflap sounds in four local populations of Flappet Larks in the Northern Province of Zambia. ( $a, b)$ Two consecutive wingbeat series of one individual at Sumbu. (c) Wingbeat series of two counterflapping individuals at Bulaya, the first bird was more distant. (d) Wingbeats of a bird recorded west of Kasama. (e, f) Wingbeat series of two individual larks at Kundabwika Falls; most of the background noise is non-avian.

The Zambian observations were made from 12 to 27 March, and the birds presumably were breeding at that season. The recorded nesting dates of $M$. rufocinnamomea in Zambia are from September to February (Benson, Brooke, Dowsett \& Irwin 1971), but many birds in the open woodland of the Northern Province appear to breed later than those of southern Zambia where most of the nesting records of the country have been taken. All birds were tape recorded in the morning between 07.00 and 10.00 , when flapping was most often heard, and the Sumbu and the Bulaya birds were recorded between 09.00 and 09.40 on 12 and 13 March. Differences in the motivational state of the birds as a possible source of the apparent differences between flapping series in the four localities seem unlikely, for the birds were recorded under very similar conditions and the successive recordings of individual birds showed a consistent stereotyped repetition of the same wingflap pattern over several minutes.

One bird at Bulaya was observed closely and was found to change from the typical pattern of multiple flaps associated with compound bursts into one of single and double 
flap sounds each separated by approximately $0.4 \mathrm{sec}$ from the next. The bird did this after it had flapped for several minutes at a height of about $60 \mathrm{~m}$ and then descended to about $20 \mathrm{~m}$ over the ground. The single and double flaps were then followed by song on the wing and while it sang the flight was without any wingbeat sounds. The simple flaps and song are shown in Figure 3. The same song was repeated several times and audiospectrographs of six renditions show it to be given identically each time. The song was loud and clear though considerably shorter than the songs of several other species of larks. This appears to be the first observation of song in $M$. rufocinnamomea inasmuch as Irwin (1958) and Wickler (1967) have reported that the species does not call in the air.

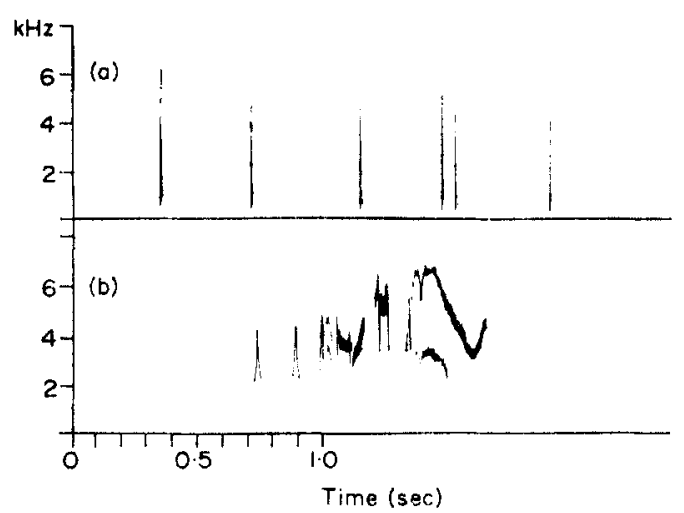

FIGURE 3. Audiospectrographs of the short version of wingbeat noises made by a Flappet Lark a Bulaya and its vocal song. The bird is the same individual whose wingflaps are illustrated as the second bird in Figure 2(c).

The communicatory signal value of flapping has not been established though presumably it advertises the presence and the motivational status of the displaying male much as song does in most other passerines. In their brushy, partly wooded habitat it seems likely that the flapping noises are more effective long-range sound signals than song would be, for birds flapping in the air can be heard for hundreds of meters and the flapping carries well in all directions. Also the production of sound high above the ground may advertise the bird over a wider area than would be true if it sang where bushy vegetation might absorb much of the energy of the sound before another bird on the ground could hear it. The fact that flapping appeared louder than the song in the Flappet Lark suggests that flapping may be primarily an agonistic territorial advertisement whereas song may be directed when females are nearby, though no birds were seen to respond to the song. Other larks, presumably other males, did respond to a flapping lark by flapping alternately with it. At one moment near Bulaya I noted three different individuals counterflapping each over its own open patch in the woodland.

The wingflaps of these larks appear to be the first instance reported of a communication signal other than a learned song or call that is shared among birds within a local population but that differs among neighbouring populations. Like the song dialects of some other birds, the wingflap dialects are of interest both because of the implications about the population biology of the species and because of their probable developmental origin.

Flappet Larks are geographically variable in Africa; White (1961), who generally recognises fewer subspecies of birds than other taxonomists, lists 15 subspecies. Geographic variation in study skins of $M$. rufocinnamomea in Zambia " is not in any way 
abrupt, affects colour only and is essentially clinal" (Irwin, in litt.). The form in the Kasama District of the Northern Province has been regarded as M. $r$. lwenarum " but not identical to it ", whereas in the Mporokoso District (which includes Bulaya and Sumbu) the birds " incline towards smithersi" (Benson et al. 1971, Benson \& Irwin 1967). Both the local flap dialects and the existence of many morphological differentiates indicate a restricted amount of dispersal in the species. The geographic scale of the local behavioural differentiates is, however, considerably finer than the scale over which morphological differences are apparent in study skins of the larks; the Sumbu and Bulaya populations were only $45 \mathrm{~km}$ distant and the occurrence of suitable habitat between these localities suggests possible additional local dialects within the area. Although the occurrence of local dialects suggests limited dispersal between local populations from one generation to the next (Thielcke 1969, Payne 1973), there evidently is sufficient dispersal over many generations to maintain considerable genetic interchange across the thousands of square kilometers that correspond to the area of the morphologically recognisable races.

In other birds examined experimentally so far, local song differences among populations of a species have been found to result from the bird hearing the song of its home population at an early age and then singing the same song at maturity. This song, once crystallised, remains that same even though the bird may later hear the songs of other populations. In most dialectal birds the song is learned before the young disperse from the grounds where they were reared (Thielcke 1969, Marler \& Mundinger 1971), though some species may disperse first and then afterwards acquire the local calls of their new neighbours (Bertram 1970). The learning of songs in dialectal birds generally involves hearing the signals at one stage of their life and then giving the same patterns themselves later. The development of wingflapping patterns that match other local individuals in the Flappet Lark may follow the same pattern.

The near-identity of the flapping series of the Nigerian larks with those of the remote Tanzanian larks may be simply a coincidence. It is unlikely that much learned behavioural tradition or genetic interchange occurs between the Nigerian and Tanzanian birds for they are not even neighbouring subspecies. Because the flapping pattern in other populations recorded differs obviously only in the number of flaps per burst (3-8, with 5-21 in the terminal burst) and the number of bursts per series ( 3 or 4 ) and all of the flap notes appear to be identical, the possible permutations of the flaps and bursts of the flapping series may be smaller than the number of local populations of this widespread species characterised by flapping dialects. The similarities of flapping patterns among some remote populations may be derived independently through a process of convergence of cultural tradition.

Facilities in Nigeria were provided by the Department of Zoology, Ahmadu Bello University, and travel in Zambia was made possible through an expedition of the National Museum of Zambia with the help of R. J. Dowsett. I thank M. P. S. Irwin for re-examining the Zambian specimens in the National Museum of Rhodesia, Bulawayo. Field work was an incidental result of the support of other research by the National Science Foundation grants GB7720 and GB29017X.

\section{REFERENCES}

Benson, C. W., Brooke, R. K., Dowsett, R. J. \& Irwin, M. P. S. 1971. The birds of Zambia. London.

Benson, C. W. \& IRwin, M. P. S. 1967. A contribution to the ornithology of Zambia. Zambia Museum Papers 1.

Bertram, B. 1970. 'The vocal behaviour of the Indian Hill Mynah, Gracula religiosa, Anim. Behav, Monogr. 3(2): 81-192.

Irwin, M. P. S. 1958. A case of geographical overlap in northern Bechuanaland of the Mirafra apiata and Mirafra rufocinnamomea group of larks. Bull. Br. Orn. Club 78: 93-94.

MARLER, P. \& Mundinger, P. 1971. Vocal learning in birds, In H. Moltz (Ed.), "The ontogeny of vertebrate behavior". New York.

PAYNE, R. B. 1973. Behavior, mimetic songs and song dialects, and relationships of the parasitic indigobirds (Vidua) of Africa. Orn. Monogr. 11. 
Thietcke, G. 1969. Geographic variation in bird vocalizations. In R. A. Hinde (Ed.), "Bird vocalizations ". Cambridge.

White, C. M. N. 1961. A revised check list of African broadbills, pittas, larks, swallows, wagtails and pipits. Lusaka.

WICKLER, W. 1967. Der " Flügelgesang” der ostafrikanischen Klapperlerche Mirafra rufocinnamomea (Salvadori). Die Vogelwelt 88: 161-165.

Museum of Zoology,

Robert B. PAyne

University of Michigan,

Ann Arbor. Michigan 48104, U.S.A.

\section{AN UNDESCRIBED EXTINCT FISH-EAGLE FROM THE CHATHAM ISLANDS}

In $1892 \mathrm{H}$. O. Forbes presented to the British Museum (Natural History) a collection of sub-Recent bird material from the Chatham Islands which included the bones of an undescribed bird of prey. The bird of prey material is not associated and consists of three tarsometatarsi, two pelves and a single scapula. As one of the tarsometatarsi is distinctly smaller than the other two and one of the pelves is a little longer and broader than the other it may be concluded that the two sexes are represented. In the Falconiformes the female tends to be larger than the male with a broader pelvis.

When E. W. Dawson examined the Forbes Collection in 1961 he noted that the specimens seemed referable to the genus Haliaeetus and appears to have intended to describe a new species within the genus, but has not done so. Our recent re-examination of the material confirms Dawson's general diagnosis, but we consider that it is referable to the related genus Ichthyophaga because of the position of the outer proximal foramen. The specimens reveal characters which justify specific recognition. The new species is described below.

DIAGNOSIS

Ichthyophaga australis sp. nov.

The tarsometatarsus differs from those of the living species of Ichthyophaga in that (1) it is much larger and more stout; (2) on the external face the outer proximal foramen is set on a slight ridge, and external to this the surface slopes anteriorly, meeting a slight ridge formed by the junction of the posterior and external surfaces. This sloping surface extends approximately $1 / 3$ along the bone from the proximal end and in this region the ridge is anteriorly displaced and poorly defined.

\section{MATERIAL}

Holotype, a right tarsometarsus (? male), BMNH A 3728. Paratypes, right and left tarsometatarsus (? female), BMNH A 3729 and A 4185; two pelves, BMNH A 3731 (? male) and A 3732 (? female) and a left scapula, BMNH A 3730.

\section{OCCURRENCE}

Superficial deposits; Chatham Island, New Zealand.

\section{DESCRIPTION}

The three tarsometatarsi are well preserved. The proximal end Plate $6(\mathrm{f})$ is widest towards its external edge, and tapers to the rounded internal cotyla to form a blunt wedge. There is a single well-developed internal calcaneal ridge rising as a narrow elongated pillar with a broader flattened head. The tendinal groove is very shallow and the external 